\title{
Intracranial Hemorrhage Caused by Non-Vitamin K Antagonist Oral Anticoagulants (NOACs) - Multicenter Retrospective Cohort Study in Japan -
}

\author{
Naoki Saji, MD, PhD; Kazumi Kimura, MD, PhD; Junya Aoki, MD, PhD; \\ Junichi Uemura, MD, PhD; Yuki Sakamoto, MD
}

Background: We conducted a multicenter retrospective cohort study to elucidate the characteristics of intracranial
hemorrhage $(\mathrm{ICH})$ in patients with atrial fibrillation treated with non-vitamin K antagonist oral anticoagulants (NOACs).

Methods and Results: We sent a questionnaire to the directors of 241 stroke centers in Japan to establish the clinical characteristics of NOAC-associated cerebral hemorrhage $(\mathrm{CH})$, including hematoma size, hematoma enlargement $(\mathrm{HE})$ and in-hospital mortality of patients treated in their institutions. We undertook a literature review to establish the clinical characteristics of warfarin-associated $\mathrm{CH}$ and compared these with our data. We received 174 responses (72.2\%), of which 67 (38.5\%) gave anonymous details of 130 eligible patients (male, 67.7\%; mean age, $77.3 \pm 8.3$ years, in-hospital mortality rate, $11.5 \%$ ). We judged that 87 of the 130 patients had presented with $\mathrm{CH}$ : one-fifth had taken antiplatelet drugs. We found that the incidences of $\mathrm{HE}$ and mortality in the 87 patients presenting with NOAC-associated $\mathrm{CH}$ were lower than would have been expected in those with warfarin-associated $\mathrm{CH}(17 \%$ vs. $26 \%$, and $16 \%$ vs. $35 \%$, respectively).

Conclusions: More than half the stroke center directors who responded to our questionnaire had not experienced cases of NOAC-associated ICH. Compared with warfarin, NOACs appear to present a lower risk of HE and death in patients with atrial fibrillation who develop $\mathrm{CH}$. (Circ $J$ 2015; 79: 1018-1023)

Key Words: Atrial fibrillation; Cerebral hemorrhage; Intracranial hemorrhage; Non-vitamin $\mathrm{K}$ antagonist oral anticoagulants

$\mathbf{P}$ atients with atrial fibrillation (AF) should be administered anticoagulant therapy to prevent thromboembolic events such as ischemic stroke. ${ }^{1-5}$ Treatment, however, may be complicated by anticoagulant-associated intracranial hemorrhage (ICH); there is a well-recognized risk of cerebral hemorrhage $(\mathrm{CH})$, resulting in poor outcome or death, in patients treated with warfarin. ${ }^{3,6-11}$ Hematoma enlargement (HE) further increases the risk in patients who have developed $\mathrm{CH}^{12,13}$

\section{Editorial p 962}

Non-vitamin K antagonist oral anticoagulants (NOACs) are increasingly in widespread use, and are frequently used as substitutes for warfarin because of their more favorable safety and efficacy profiles. ${ }^{3,6-10}$ There have been many reports that NOACs carry a lower risk of ICH than warfarin. $3,8-11,14,15$ Asians have a higher risk of warfarin-associated ICH than nonAsians $;{ }^{16,17}$ however, the characteristics of NOAC-associated
ICH in Asians have not yet been established.

The aim of this study was to use a nationwide questionnaire survey in Japan to elucidate the characteristics of AF patients taking NOACs who developed $\mathrm{CH}$, and to establish the extent of the relationship between treatment with NOACs and adverse clinical outcomes such as HE and death.

\section{Methods}

\section{Study Design}

We conducted a nationwide, multicenter, retrospective cohort questionnaire survey in May 2014. The questionnaire was sent by post to the directors of 241 stroke centers in Japan that met 2 criteria: (1) providing acute stroke management as defined by the Japanese Neurosurgical Society and/or the Societas Neurologica Japonica, and (2) equipped as a stroke unit and/ or a specialized stroke care unit with or without intensive care unit provision. Participating hospitals were selected from 7

Received November 4, 2014; revised manuscript received December 15, 2014; accepted January 4, 2015; released online February 20, 2015 Time for primary review: 5 days

Department of Stroke Medicine, Kawasaki Medical School, Kurashiki (N.S., J.U.); Department of Neurological Science, Nippon Medical School Graduate School of Medicine, Tokyo (K.K., J.A., Y.S.), Japan

Mailing address: Naoki Saji, MD, PhD, Associate Professor, Department of Stroke Medicine, Kawasaki Medical School, 577 Matsushima, Kurashiki 701-0192, Japan. E-mail: sajink@nifty.com

ISSN-1346-9843 doi:10.1253/circj.CJ-14-1209

All rights are reserved to the Japanese Circulation Society. For permissions, please e-mail: cj@j-circ.or.jp 


\section{A}

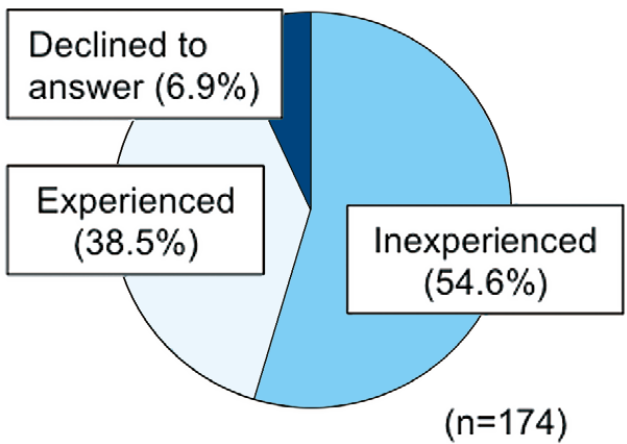

B

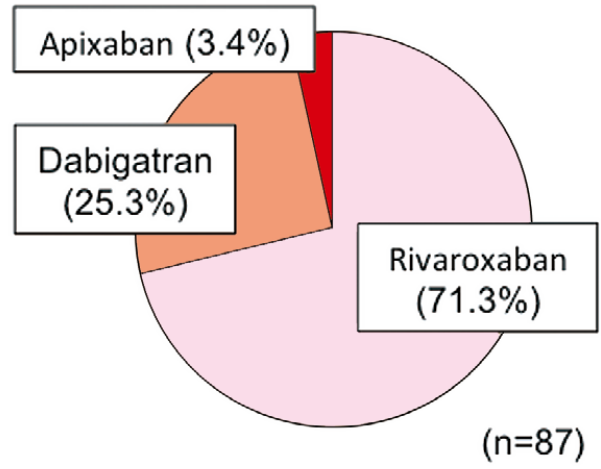

Figure. (A) Distribution of percent respondents regarding experiences of NOAC-associated ICH in answer to the question: "Did any neurologist or neurosurgeon belonging to your hospital experience patients with atrial fibrillation who developed ICH during NOAC therapy?" (B) Distribution of anticoagulation strategy before the onset of NOAC-associated $\mathrm{CH}$. $\mathrm{CH}$, cerebral hemorrhage; $\mathrm{ICH}$, intracranial hemorrhage; NOAC, non-vitamin $\mathrm{K}$ antagonist oral anticoagulant.

districts according to juridical regions defined by the Ministry of Health, Labor and Welfare, Japan, depending on the population residing in each district: Hokkaido (18 hospitals); Tohoku (17 hospitals); Kanto (76 hospitals); Chubu (35 hospitals); Kinki (36 hospitals), Chugoku-Shikoku (26 hospitals), and Kyushu (33 hospitals). Details of the questionnaire and response rates are provided in Supplementary File 1. A covering letter accompanying the survey informed recipients that: (1) any neurologist or neurosurgeon at the director's institution who had experienced at least 1 case of $\mathrm{ICH}$ among patients with AF during NOAC therapy between March 2011 and April 2014 was eligible to complete the survey; (2) that participation was voluntary; and (3) that responses should comprise anonymized patient data and be approved by the center director. Responses not approved by the stroke center director were excluded. Data were collected from returned questionnaires by research assistants and a neurologist (N.S.). The study complied with the Declaration of Helsinki and was approved by the Institutional Review Board of Kawasaki Medical School Hospital. The study was registered with the UMIN Clinical Trials Registry (UMIN000014230).

\section{Questionnaire}

We categorized ICH into the 3 types: $\mathrm{CH}$, subarachnoid hemorrhage (SAH) and subdural hematoma (SDH). The characteristics of the hematoma such as location and volume (calculated using the ABC/2 formula, ${ }^{12,13}$ Appendix S1) were recorded. Hematoma expansion was defined as $>33 \%$ enlargement in hematoma volume on subsequent images compared with the baseline hematoma volume on admission. ${ }^{13}$ Treatment with a NOAC was defined as any use of dabigatran, rivaroxaban or apixaban. The questionnaire also required the inclusion of: (1) demographic data such as age, sex and CHADS 2 score $^{2}$; (2) risk factors; (3) medical history; (4) medications on admission (antiplatelet drugs, warfarin, NOACs, or dual therapy defined as use of both a NOAC and an antiplatelet drug); (5) the results of laboratory investigations; (6) brain imaging findings; (7) National Institutes of Health Stroke Scale (NIHSS) score on admission; (8) details of treatment after admission; (9) clinical outcomes such as modified Rankin scale (mRS) scores at discharge, discharge destination and death in hospital.

\section{Literature Search and Data Extraction}

We undertook a literature review to establish the clinical characteristics of warfarin-associated $\mathrm{CH}$ and compared these with our data. Relevant literature was identified by searches of Medline using the search terms "NOAC" or "non-vitamin K antagonist oral anticoagulants", "warfarin" or "oral anticoagulants", and "ICH" or "CH" in the date range January 2001 to September 2014. Only papers in English were reviewed. We manually reviewed all papers, selected relevant references and extracted the data.

\section{Statistical Analysis}

Continuous, ordinal and categorical variables are expressed as mean \pm standard deviation, median and interquartile range, and frequencies and proportions (percentages), and were compared using the unpaired Student's t-test, Wilcoxon rank-sum test, and $\chi^{2}$ test, respectively. We assessed the relationships between the characteristics of the patients who developed ICH, in particular those who developed $\mathrm{CH}$, and therapy with a NOAC, $\mathrm{HE}$ and in-hospital death. We compared the incident rates of $\mathrm{HE}$ and death between patients treated with a NOAC and those with warfarin, using data obtained from the literature review. We identified the mean incident rates of $\mathrm{HE}$ and death in the warfarin group using the published data available, but did not undertake formal analyses as we did not have access to raw data. Odds ratios (ORs) are presented with $95 \%$ confidence intervals (CIs). All comparisons were 2 -tailed and $\mathrm{P}<0.05$ was considered statistically significant. All data were analyzed using the JMP 11.2 software package (SAS Institute Inc, Cary, NC, USA).

\section{Results}

\section{Patients}

Of 241 stroke center directors, 174 returned the questionnaire (Figure S1). Those who participated are listed in Appendix S2. More than half (95 of 174 respondents, 54.6\%) had not experienced a case of a patient with AF treated by a NOAC and complicated by $\mathrm{ICH}$, but 67 responded with details of 130 eligible patients (Figure A). The diagnoses of ICH were as follows: $\mathrm{CH}(\mathrm{n}=87,67.0 \%), \mathrm{SDH}(\mathrm{n}=30,23.0 \%), \mathrm{SAH}(\mathrm{n}=6$, 


\begin{tabular}{|c|c|c|c|c|c|c|}
\hline & \multirow{2}{*}{$\mathrm{ICH}$} & \multicolumn{5}{|c|}{ Classification of ICH } \\
\hline & & $\mathrm{CH}$ & SDH & SAH & Other & $P$ value \\
\hline \multicolumn{7}{|l|}{ Demographics } \\
\hline n (\%) & $130(100)$ & $87(67.0)$ & $30(23.0)$ & $6(4.6)$ & $7(5.4)$ & \\
\hline Age, years & $77.3 \pm 8.3$ & $76.2 \pm 8.1$ & $80.0 \pm 8.4$ & $81.2 \pm 9.7$ & $76.7 \pm 6.7$ & 0.127 \\
\hline Male sex, n (\%) & $88(67.7)$ & $62(71.3)$ & $21(70.0)$ & $3(50.0)$ & $2(28.6)$ & 0.096 \\
\hline \multicolumn{7}{|l|}{ Physical status } \\
\hline $\mathrm{SBP}, \mathrm{mmHg}$ & $158(136-179)$ & $164(140-185)$ & $140(129-165)$ & $164(128-179)$ & $158(141-185)$ & 0.017 \\
\hline $\mathrm{DBP}, \mathrm{mmHg}$ & $85(74-100)$ & $87(76-103)$ & $74(65-88)$ & $88(75-100)$ & $94(79-109)$ & 0.009 \\
\hline NIHSS score & $12(3-20)$ & $14(4-21)$ & $5(2-11)$ & $2(0-28)$ & $9(2-12)$ & 0.141 \\
\hline $\mathrm{CHADS}_{2}$ score & $3(1-4)$ & $3(2-4)$ & $3(2-4)$ & $4(2-4)$ & $4(3-5)$ & 0.092 \\
\hline \multicolumn{7}{|l|}{ Risk factors } \\
\hline Hypertension, n (\%) & $103(79.2)$ & 69 (79.3) & $24(80.0)$ & 5 (83.3) & $5(71.4)$ & 0.331 \\
\hline Diabetes mellitus, $\mathrm{n}(\%)$ & $34(26.2)$ & $20(23.0)$ & $9(30.0)$ & $2(33.3)$ & $3(42.9)$ & 0.604 \\
\hline CKD, n (\%) & $103(79.2)$ & $67(77.0)$ & $25(92.6)$ & $6(100)$ & $5(71.4)$ & 0.350 \\
\hline \multicolumn{7}{|l|}{ Laboratory data } \\
\hline Serum creatinine, mg/dl & $0.8(0.62-0.91)$ & $0.81(0.67-0.98)$ & $0.80(0.64-0.91)$ & $0.66(0.58-0.86)$ & $0.60(0.52-0.7)$ & 0.059 \\
\hline eGFR & $39.6(29.3-49.4)$ & $38.4(30.7-50.4)$ & $39.9(24.3-45.7)$ & $37.5(32.4-46.9)$ & $55.5(33.9-66.3)$ & 0.233 \\
\hline \multicolumn{7}{|l|}{ Premorbid medication } \\
\hline APs, n (\%) & $28(21.5)$ & $18(20.7)$ & $5(16.7)$ & 2 (33.3) & $3(42.9)$ & 0.418 \\
\hline NOACs & & & & & & 0.004 \\
\hline Dabigatran, n (\%) & $42(32.3)$ & $22(25.3)$ & $16(53.3)$ & $3(50.0)$ & $1(14.3)$ & \\
\hline Rivaroxaban, n (\%) & $82(63.1)$ & $62(71.3)$ & $13(43.3)$ & $3(50.0)$ & $4(57.1)$ & \\
\hline Apixaban, n (\%) & $6(4.6)$ & $3(3.5)$ & $1(3.3)$ & $0(0)$ & $2(28.6)$ & \\
\hline $\begin{array}{l}\text { Premorbid antihypertensive } \\
\text { drug, } \mathrm{n}(\%)\end{array}$ & $95(73.1)$ & $60(69.0)$ & $24(80.0)$ & $5(83.3)$ & $6(85.7)$ & 0.500 \\
\hline \multicolumn{7}{|l|}{ Treatment } \\
\hline $\begin{array}{l}\text { Antihypertensive therapy } \\
\text { after onset of ICH, n (\%) }\end{array}$ & $102(78.5)$ & $76(87.4)$ & $17(56.7)$ & $5(83.3)$ & $4(57.1)$ & 0.002 \\
\hline Vitamin K, n (\%) & $3(2.3)$ & $2(2.3)$ & $0(0)$ & $1(16.7)$ & $0(0)$ & 0.095 \\
\hline PCC, n (\%) & $13(10.0)$ & $9(10.3)$ & $3(10.0)$ & $1(16.7)$ & $0(0)$ & 0.781 \\
\hline Surgery, n (\%) & $35(26.9)$ & $11(12.6)$ & $21(70.0)$ & $3(50.0)$ & $0(0)$ & $<0.001$ \\
\hline \multicolumn{7}{|l|}{ Discharge } \\
\hline In-hospital death, $\mathrm{n}(\%)$ & $15(11.5)$ & $14(16.1)$ & $0(0)$ & $1(16.7)$ & $0(0)$ & 0.013 \\
\hline mRS 0-2 at discharge & $48(36.9)$ & $20(23.0)$ & $22(73.3)$ & 2 (33.3) & $4(57.1)$ & $<0.001$ \\
\hline
\end{tabular}

Data are presented as mean \pm standard deviation, median (interquartile range), or number (\%). AP, antiplatelet drug; $\mathrm{CH}$, cerebral hemorrhage; CKD, chronic kidney disease; DBP, diastolic blood pressure; eGFR, estimated glomerular filtration rate; HE, hematoma enlargement; $\mathrm{ICH}$, intracranial hemorrhage; mRS, modified Rankin scale; NIHSS, National Institutes of Health Stroke Scale; NOAC, non-vitamin K antagonist oral anticoagulant; PCC, prothrombin complex concentrate; SAH, subarachnoid hemorrhage; SBP, systolic blood pressure; SDH, subdural hematoma.

$4.6 \%)$ and other $(n=7,5.4 \%)$. Of the 130 cases reported, the median $\mathrm{CHADS}_{2}$ score was 3, 103 had chronic kidney disease (CKD), 28 had been receiving dual anticoagulant therapy, 13 were treated with prothrombin complex concentrate (PCC) and $15(11.5 \%)$ died during their hospitalization (Table 1). The complete data are shown in Table $\mathbf{S 1 .}$

\section{NOAC-Associated CH}

The characteristics of the 87 patients who developed $\mathrm{CH}$ were as follows: the median $\mathrm{CHADS}_{2}$ score was 3, 67 had CKD, 18 had been receiving dual therapy, $12(13.8 \%)$ developed HE and $14(16.1 \%)$ died during hospitalization (Table 1). A representative case is shown in Figure S2. The anticoagulation strategy that had been adopted in these patients was as follows (Figure B): low-dose rivaroxaban $(10 \mathrm{mg} /$ day, $\mathrm{n}=33)$, highdose rivaroxaban $(15 \mathrm{mg} /$ day, $\mathrm{n}=29)$, low-dose dabigatran $(\leq 220 \mathrm{mg} /$ day, $\mathrm{n}=17)$, high-dose dabigatran $(300 \mathrm{mg} /$ day, $\mathrm{n}=5)$, and apixaban (10 mg/day, $\mathrm{n}=3$ ).

\section{Rivaroxaban vs. Dabigatran}

Among the patients who developed $\mathrm{ICH}$, patients taking rivaroxaban were at significantly higher risk of $\mathrm{CH}(76.8 \%$ vs. $52.4 \%$, respectively; $\mathrm{P}=0.008)$ and $\mathrm{HE}(19.4 \%$ vs. $0 \%$, respectively; $\mathrm{P}=0.031$, Table 2) than those taking dabigatran, but at significantly lower risk of SDH than those taking dabigatran ( $14.6 \%$ vs. $38.1 \%$, respectively; $\mathrm{P}=0.006$ ).

\section{NOACs vs. Warfarin}

We obtained data of warfarin-associated $\mathrm{CH}$ from our literature review. ${ }^{12,13,18-26}$ The initial size of the hematoma was at least equal to or smaller in patients treated with NOACs compared with a control group of patients treated with warfarin whose outcomes were published in previous studies (Table 3). The incidence of $\mathrm{HE}$ and death in those taking NOACs described by our respondents was lower than in the warfarin control group ( $14 \%$ vs. $26 \%$, and $17 \%$ vs. $35 \%$, respectively; Table 3), although lack of raw data from the warfarin studies 


\begin{tabular}{lccc|}
\multicolumn{3}{l}{ Table 2. Comparison of Patients Presenting With CH During Therapy With Dabigatran or Rivaroxaban } \\
$\mathrm{n}$ & Dabigatran & Rivaroxaban & P value \\
Age, years & 22 & 62 & $0.153^{\star}$ \\
Male sex, $\mathrm{n}(\%)$ & $77.9 \pm 7.8$ & $75.8 \pm 8.3$ & $0.183^{\ddagger}$ \\
Premorbid mRS 0-2, n (\%) & $13(59.1)$ & $46(74.2)$ & $0.204^{\ddagger}$ \\
NIHSS score & $6(27.3)$ & $9(14.5)$ & $0.379^{\dagger}$ \\
CHADS2 score & $12(3-21)$ & $17(7-24)$ & $0.895^{\dagger}$ \\
Hematoma volume on admission, cm & $3(2-3)$ & $0.734^{\dagger}$ \\
HE, $\mathrm{n}$ (\%) & $14.4(4.5-48.5)$ & $15.8(6-34)$ & $0.031^{\ddagger}$ \\
In-hospital death, $\mathrm{n}(\%)$ & $0(0)$ & $12(19.4)$ & $0.498^{\ddagger}$ \\
\hline
\end{tabular}

*Unpaired Student's t-test; †Wilcoxon rank-sum test; $\neq \chi 2$ test. Abbreviations as in Table 1.

\begin{tabular}{|c|c|c|c|c|c|}
\hline Reference no. & $\begin{array}{c}\text { No. of } \\
\text { patients }\end{array}$ & Anticoagulant & $\begin{array}{l}\text { Hematoma, } \\
\mathbf{c m}^{3}\end{array}$ & HE, n (\%) & $\begin{array}{c}\text { Mortality, } \\
\text { n (\%) }\end{array}$ \\
\hline \multicolumn{6}{|l|}{ Warfarin } \\
\hline Witt et al ${ }^{18}$ & 259 & Warfarin & NA & NA & $99(27)$ \\
\hline Dowlashahi et al ${ }^{19}$ & $71^{*}$ & Warfarin & $16(32)$ & $15 / 33(46)$ & $30(42)$ \\
\hline Alonso et $\mathrm{al}^{20}$ & 723 & Warfarin & NA & NA & 244 (34) \\
\hline Chen et $\mathrm{al}^{21}$ & 94 & Warfarin & $41 \pm 39$ & NA & $36(38)^{d}$ \\
\hline Horstmann et al ${ }^{22}$ & 51 & Warfarin & $20(8-49)$ & 4/32 (13) & $23(45)^{c}$ \\
\hline Kuwashiro et $\mathrm{al}^{12}$ & 41 & Warfarin & $34 \pm 55$ & $15(39)$ & $24(59)^{a}$ \\
\hline Toyoda et $\mathrm{al}^{13}$ & 67 & Warfarin & $23 \pm 31$ & $16(37)$ & $11(16)^{b}$ \\
\hline Toyoda et al ${ }^{13}$ & 21 & Warfarin+AP & $29 \pm 41$ & $5(45)$ & $9(43)^{b}$ \\
\hline Liotta et al ${ }^{23}$ & 56 & Warfarin & $20(8-76)$ & NA & $21(37)$ \\
\hline Hagii et al24 & 56 & Warfarin & $11(7-34)$ & $10 / 48(21)$ & $10(18)^{a}$ \\
\hline Total & 1,440 & Warfarin & $N A^{\ddagger}$ & $65 / 250(26)$ & 507 (35) \\
\hline \multicolumn{6}{|l|}{ NOAC } \\
\hline Komori et $\mathrm{al}^{25}$ & $2^{\dagger}$ & Dabigatran & 1 and 5 & $0(0)$ & $0(0)^{a}$ \\
\hline Simonsen et al ${ }^{26}$ & 1 & Dabigatran & 15 & $1(100)$ & $1(100)^{b}$ \\
\hline Present study & 87 & NOAC & $15(6-38)$ & $12 / 74(14)$ & $14(17)^{\mathrm{a}}$ \\
\hline Total & 90 & NOAC & $15(5-34)$ & $13 / 77(17)$ & $15(16)$ \\
\hline
\end{tabular}

aln-hospital death; bdeath at 3 weeks; 'death at 3 months; ddeath at 1 month. ${ }^{*}$ Patients treated with prothrombin complex concentrates for anticoagulant-associated $\mathrm{ICH}$ were analyzed. ${ }^{\dagger}$ Among 8 patients who developed $\mathrm{ICH}$, the

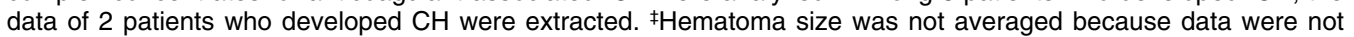
presented consistently, with either mean or median values reported by other investigators. NA, not applicable. Other abbreviations as in Table 1.

meant that these differences were not subject to formal statistical analysis.

\section{In-Hospital Death}

Patients presenting with ICH who died during their hospitalization were significantly more likely to have sustained $\mathrm{CH}$, have elevated serum creatinine concentration on admission and were less likely to have been taking an antihypertensive drug before admission (Table S2). Patients presenting with $\mathrm{CH}$ who died during their hospitalization had significantly larger hematomas on admission and more elevated admission serum creatinine concentration and were more likely to have been taking antiplatelet drugs (Table S3).

\section{Discussion}

We used a nationwide anonymous questionnaire survey to establish the clinical outcomes of Japanese patients who developed NOAC-associated $\mathrm{CH}$. We found that more than half of the
241 stroke centers in Japan that participated had not treated 1 or more patients with NOAC-associated $\mathrm{ICH}$, suggesting that the incidence is low. Those with clinical experience of NOACassociated $\mathrm{CH}$ reported the initial size of the hematoma as smaller, and lower incident rates of both $\mathrm{HE}$ and death than would have been expected if their patients had been anticoagulated with warfarin.

Numerous studies have reported the characteristics of NOACassociated ICH. ${ }^{9,24-27}$ Furthermore, a recent meta-analysis showed that NOACs significantly reduced the risk of ICH compared with warfarin (OR $0.49,95 \%$ CI $0.36-0.65) .{ }^{28}$ The main difference regarding the anticoagulant mechanism of action of NOACs is that they do not affect the plasma concentration of factor VII or VIIa, but warfarin suppresses factor VII production; ${ }^{25,28}$ both factors are essential in the coagulation cascade. When patients with ischemic stroke undergo thrombolysis, NOACs could also be neuroprotective by inhibiting the activation of matrix metalloproteinase- 9 and preventing disruption of astrocytes and pericytes, thereby reducing the further risk 
of $\mathrm{ICH} .{ }^{29}$ These differences may explain why treatment with NOACs appears to be associated with lower risks of $\mathrm{HE}$ and death in patients with $\mathrm{ICH}$.

Treatment with PCC or other hemostatic agents has been proposed as a means of preventing HE in patients with NOACassociated $\mathrm{ICH} ;{ }^{16,25}$ however, it is still unclear whether acute reversal is necessary to improve outcome. ${ }^{26}$ In our cohort, 12 of the 13 patients treated with PCC survived, although the data were not statistically significant and may have been influenced by selection bias. For example, patients who developed very large hematomas presenting with severe neurological deficit may have been managed conservatively or given palliative care rather than PCC or surgery. This issue will need to be addressed in future studies.

There has been a great deal of interest in establishing whether there are therapeutic differences between the NOACs, and differences in the incidence of adverse events. In our study, the incidence of HE was lower in patients taking dabigatran compared with those taking rivaroxaban, but this finding may have been influenced by our relatively small sample size and nonsignificant trends suggesting more favorable premorbid mRS $(0-2)$ and lower initial NIHSS scores in patients who had been taking dabigatran. However, even when taking these factors into consideration, the findings of other studies suggest that there may be differences between the groups. For example, there is reportedly a substantially lower risk of ICH with dabigatran than warfarin (hazard ratio $0.32,95 \%$ CI $0.20-0.50),{ }^{14}$ but the risk with rivaroxaban is broadly comparable to that with warfarin (hazard ratio $1.17,95 \%$ CI 0.66-2.05). ${ }^{30}$ Furthermore, bleeding event rates in patients aged $\geq 75$ years taking rivaroxaban are reportedly higher than in those taking warfarin. ${ }^{31}$ Although NOACs consistently reduce the incidence of $\mathrm{ICH}$ regardless of the site of the bleed within or outside the brain parenchyma, ${ }^{28}$ we found significant differences between the rate of $\mathrm{CH}$ and $\mathrm{SDH}$ in the dabigatran and rivaroxaban groups. Our study was not designed to offer an explanation for the differences in clinical outcomes that we found, but it is possible that the different mechanisms of action of the drugs may be an explanation: rivaroxaban selectively inhibits factor Xa whereas dabigatran inhibits thrombin. ${ }^{17,28}$

\section{Study Limitations and Strengths}

We were unable to adjust for variables that may influence $\mathrm{HE}$ and death because of the retrospective design of the study, and we did not conduct a meta-analysis. Despite the high response rate to our survey, selection bias may have occurred. We did not ask our respondents for details of warfarin-induced $\mathrm{CH}$, as we judged that these data would be substantially more onerous for respondents to collect, which might adversely influence the response rate. Furthermore, we did not seek denominator data of NOAC use in the populations served by the stroke centers, which would have allowed us to calculate the incidence of NOAC-induced CH. The HAS-BLED score ${ }^{3,32}$ was not assessed. The increasing global popularity of NOACs means that there are still some safety issues that need to be urgently addressed, and their use substantially increases prescribing costs. It will be important to establish whether the increased costs compared with warfarin are counterbalanced by reductions in the costs of treating stroke, its consequences, ${ }^{33}$ or the other complications of anticoagulation. Nonetheless, our study had some notable strengths. We obtained a large sample of patients with NOAC-associated $\mathrm{ICH}$, in particular NOAC-associated $\mathrm{CH}$, allowing us to make some comparisons of dabigatran and rivaroxaban in addition to comparisons of warfarin and NOACs. Although such comparisons of dabigatran and rivaroxaban have not yet been undertaken, our data could be used to inform the design of larger controlled trials.

\section{Conclusions}

The incidence of NOACs-associated $\mathrm{CH}$ in Japanese patients with AF appears to be low. Patients who developed NOACassociated $\mathrm{CH}$ had lower incident rates of both $\mathrm{HE}$ and mortality than would have been expected had they been treated with warfarin. Comparisons of the incidence and risk of $\mathrm{CH}$ among the NOACs, and between NOACs and warfarin, should be investigated in future studies.

\section{Acknowledgments}

Dr Saji received a research grant from the Grant-in-Aid for Scientific Research program (No. 26870765) of the Japan Society for the Promotion of Science.

\section{References}

1. Singer DE, Chang Y, Fang MC, Borowsky LH, Pomernacki NK, Udaltsova N, et al. The net clinical benefit of warfarin anticoagulation in atrial fibrillation. Ann Intern Med 2009; 151: 297-305.

2. Camm AJ, Lip GY, De Caterina R, Savelieva I, Atar D, Hohnloser $\mathrm{SH}$, et al. 2012 focused update of the ESC Guidelines for the Management of Atrial Fibrillation: An update of the 2010 ESC Guidelines for the Management of Atrial Fibrillation: Developed with the special contribution of the European Heart Rhythm Association. Eur Heart J 2012; 33: 2719-2747.

3. January CT, Wann LS, Alpert JS, Calkins H, Cleveland JC, Cigarroa JE, et al. 2014 AHA/ACC/HRS guideline for the management of patients with atrial fibrillation: Executive summary: A report of the American College of Cardiology/American Heart Association Task Force on Practice Guidelines and the Heart Rhythm Society. Circulation 2014; 130: $2071-2104$.

4. Inoue H, Atarashi H, Okumura K, Yamashita T, Kumagai N, Origasa $\mathrm{H}$. Thromboembolic events in paroxysmal vs. permanent non-valvular atrial fibrillation. Circ J 2014; 78: 2388-2393.

5. Hart RG, Diener HC, Yang S, Connolly SJ, Wallentin L, Reilly PA, et al. Intracranial hemorrhage in atrial fibrillation patients during anticoagulation with warfarin or dabigatran: The RE-LY trial. Stroke 2012; 43: $1511-1517$.

6. Kosiuk J, Koutalas E, Doering M, Nedios S, Sommer P, Rolf S, et al. Comparison of dabigatran and uninterrupted warfarin in patients with atrial fibrillation undergoing cardiac rhythm device implantations. Circ J 2014; 78: 2402-2407.

7. Tanahashi N, Hori M, Matsumoto M, Momomura S, Uchiyama S, Goto S, et al. Rivaroxaban versus warfarin in Japanese patients with nonvalvular atrial fibrillation for the secondary prevention of stroke: A subgroup analysis of J-ROCKET AF. J Stroke Cerebrovasc Dis 2013; 22: 1317-1325.

8. Ruff CT, Giugliano RP, Braunwald E, Hoffman EB, Deenadayalu $\mathrm{N}$, Ezekowitz MD, et al. Comparison of the efficacy and safety of new oral anticoagulants with warfarin in patients with atrial fibrillation: A meta-analysis of randomised trials. Lancet 2014; 383: $955-$ 962.

9. Cameron C, Coyle D, Richter T, Kelly S, Gauthier K, Steiner S, et al. Systematic review and network meta-analysis comparing antithrombotic agents for the prevention of stroke and major bleeding in patients with atrial fibrillation. BMJ Open 2014; 4: e004301, doi:10.1136/bmjopen-2013-004301.

10. Sabir I, Khavandi K, Brownrigg J, Camm AJ. Oral anticoagulants for Asian patients with atrial fibrillation. Nat Rev Cardiol 2014; 11: 290-303.

11. Heidbuchel H, Verhamme P, Alings M, Antz M, Hacke W, Oldgren $\mathrm{J}$, et al. European Heart Rhythm Association Practical Guide on the use of new oral anticoagulants in patients with non-valvular atrial fibrillation. Europace 2013; 15: 625-651.

12. Kuwashiro T, Yasaka M, Itabashi R, Nakagaki H, Miyashita F, Naritomi H, et al. Enlargement of acute intracerebral hematomas in patients on long-term warfarin treatment. Cerebrovasc Dis 2010; 29: 446-453.

13. Toyoda K, Yasaka M, Nagata K, Nagao T, Gotoh J, Sakamoto T, et al. Antithrombotic therapy influences location, enlargement, and mortality from intracerebral hemorrhage: The Bleeding with Antithrombotic Therapy (BAT) retrospective study. Cerebrovasc Dis 2009; 27: $151-159$. 
14. Hernandez I, Baik SH, Piñera A, Zhang Y. Risk of bleeding with dabigatran in atrial fibrillation. JAMA Intern Med 2015; 175: 18-24.

15. Graham DJ, Reichman ME, Wernecke M, Zhang R, Southworth MR, Levenson M, et al. Cardiovascular, bleeding, and mortality risks in elderly Medicare patients treated with dabigatran or warfarin for non-valvular atrial fibrillation. Circulation 2015; 131: 157-164.

16. Shen AY, Yao JF, Brar SS, Jorgensen MB, Chen W. Racial/ethnic differences in the risk of intracranial hemorrhage among patients with atrial fibrillation. J Am Coll Cardiol 2007; 50: 309-315.

17. Hankey GJ, Stevens SR, Piccini JP, Lokhnygina Y, Mahaffey KW, Halperin JL, et al. Intracranial hemorrhage among patients with atrial fibrillation anticoagulated with warfarin or rivaroxaban: The rivaroxaban once daily, oral, direct factor Xa inhibition compared with vitamin $\mathrm{K}$ antagonism for prevention of stroke and embolism trial in atrial fibrillation. Stroke 2014; 45: 1304-1312.

18. Witt DM, Delate T, Hylek EM, Clark NP, Crowther MA, Dentali F, et al. Effect of warfarin on intracranial hemorrhage incidence and fatal outcomes. Thromb Res 2013; 132: 770-775.

19. Dowlatshahi D, Butcher KS, Asdaghi N, Nahirniak S, Bernbaum ML, Giulivi A, et al. Poor prognosis in warfarin-associated intracranial hemorrhage despite anticoagulation reversal. Stroke 2012; 43: $1812-1817$.

20. Alonso A, Bengtson LG, MacLehose RF, Lutsey PL, Chen LY, Lakshminarayan K. Intracranial hemorrhage mortality in atrial fibrillation patients treated with dabigatran or warfarin. Stroke 2014; 45: 2286-2291.

21. Chen YW, Tang SC, Tsai LK, Yeh SJ, Chiou HY, Yip PK, et al. Pre-ICH warfarin use, not antiplatelets, increased case fatality in spontaneous ICH patients. Eur J Neurol 2013; 20: 1128-1134.

22. Horstmann S, Rizos T, Lauseker M, Möhlenbruch M, Jenetzky E, Hacke W, et al. Intracerebral hemorrhage during anticoagulation with vitamin $\mathrm{K}$ antagonists: A consecutive observational study. $J$ Neurol 2013; 260: 2046-2051.

23. Liotta EM, Garg RK, Temes RE, John S, Lee VH, Bleck TP, et al. Warfarin-associated intracerebral hemorrhage is inadequately treated at community emergency departments. Stroke 2012; 43: 2503-2505.

24. Hagii J, Tomita H, Metoki N, Saito S, Shiroto H, Hitomi H, et al. Characteristics of intracerebral hemorrhage during rivaroxaban treatment: Comparison with those during warfarin. Stroke 2014; 45: 2805-2807.

25. Komori M, Yasaka M, Kokuba K, Matsuoka H, Fujimoto S, Yoshida $\mathrm{M}$, et al. Intracranial hemorrhage during dabigatran treatment. Circ J 2014; 78: $1335-1341$.

26. Simonsen CZ, Steiner T, Tietze A, Damgaard D. Dabigatranrelated intracerebral hemorrhage resulting in hematoma expansion. J Stroke Cerebrovasc Dis 2014; 23: e133-e134, doi:10.1016/j. jstrokecerebrovasdis.2013.08.011.

27. Hankey GJ. Intracranial hemorrhage and novel anticoagulants for atrial fibrillation: What have we learned? Curr Cardiol Rep 2014;
16: 480 .

28. Chatterjee S, Sardar P, Biondi-Zoccai G, Kumbhani DJ. New oral anticoagulants and the risk of intracranial hemorrhage: Traditional and Bayesian meta-analysis and mixed treatment comparison of randomized trials of new oral anticoagulants in atrial fibrillation. JAMA Neurol 2013; 70: 1486-1490.

29. Kono S, Yamashita T, Deguchi K, Omote Y, Yunoki T, Sato K, et al. Rivaroxaban and apixaban reduce hemorrhagic transformation after thrombolysis by protection of neurovascular unit in rat. Stroke 2014; 45: 2404-2410

30. Laliberté F, Cloutier M, Nelson WW, Coleman CI, Pilon D, Olson $\mathrm{WH}$, et al. Real-world comparative effectiveness and safety of rivaroxaban and warfarin in nonvalvular atrial fibrillation patients. Curr Med Res Opin 2014; 30: 1317-1325.

31. Hori M, Matsumoto M, Tanahashi N, Momomura S, Uchiyama S, Goto S, et al. Rivaroxaban vs. Warfarin in Japanese patients with non-valvular atrial fibrillation in relation to age. Circ J 2014; 78: $1349-1356$.

32. Okumura K, Inoue H, Atarashi H, Yamashita T, Tomita H, Origasa $\mathrm{H}$, et al. Validation of $\mathrm{CHA}_{2} \mathrm{DS}_{2}-\mathrm{VASc}$ and HAS-BLED scores in Japanese patients with nonvalvular atrial fibrillation: An analysis of the J-RHYTHM Registry. Circ J 2014; 78: 1593-1599.

33. Harrington AR, Armstrong EP, Nolan PE, Malone DC. Cost-effectiveness of apixaban, dabigatran, rivaroxaban, and warfarin for stroke prevention in atrial fibrillation. Stroke 2013; 44: 1676-1681.

\section{Supplementary Files}

Supplementary File 1

Methods

Figure S1. Study flow chart.

Figure S2. Representative case from among those reported by respondents to the questionnaire.

Table S1. Full demographic and clinical characteristics of patients in atrial fibrillation presenting with ICH during treatment with NOAC

Table S2. Characteristics of patients presenting with ICH during NOAC treatment, comparing those who survived with those who died

Table S3. Characteristics of patients presenting with $\mathrm{CH}$ during NOAC treatment, comparing those who survived with those who died

Appendix S1. The ABC/2 Method

Appendix S2. Personnel

Please find supplementary file(s);

http://dx.doi.org/10.1253/circj.CJ-14-1209 